\title{
Tyrosine Kinase Inhibitor Suppresses Coronary Arteriosclerotic Changes and Vasospastic Responses Induced by Chronic Treatment with Interleukin-1 $\beta$ in Pigs In Vivo
}

\author{
Akira Ito, Hiroaki Shimokawa, Toshiaki Kadokami, Yoshihiro Fukumoto, * M. Koji Owada, ${ }^{\ddagger}$ Tadayoshi Shiraishi, \\ Ryuichi Nakaike, Tsuneo Takayanagi, Kensuke Egashira, and Akira Takeshita \\ Research Institute of Angiocardiology and Cardiovascular Clinic, Kyushu University School of Medicine, Fukuoka 812, Japan; *Institute \\ of Molecular and Cellular Biology for Pharmaceutical Science, Kyoto Pharmaceutical University, Kyoto 607, Japan; and ${ }^{\ddagger}$ Biochemical \\ Research Laboratories, Kaneka Corporation, Takasago 676, Japan
}

\begin{abstract}
We recently demonstrated that chronic treatment with IL$1 \beta$ induces coronary arteriosclerotic changes and vasospastic responses to autacoids in pigs in vivo and that those responses are importantly mediated by PDGF. The receptors for PDGF and other major growth factors are known to have tyrosine kinase activity. We therefore investigated the effects of a selective tyrosine kinase inhibitor, ST 638, on those responses induced by $\mathrm{IL-1 \beta}$ in our swine model. Intimal thickening and coronary vasospastic responses to serotonin and histamine were induced at the site of the coro-

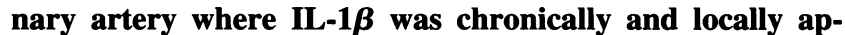
plied. These responses were significantly suppressed in a dose-dependent manner by cotreatment with ST 638. In addition, ST 494, which is an inactive form of ST 638, did not inhibit those responses. The treatment with ST 638 alone did not affect the coronary vasoconstricting responses to the autacoids. Immunoblotting using an antibody to phosphotyrosines confirmed the inhibitory effects of ST 638 on the tyrosine phosphorylations induced by IL-1ß. These results thus suggest that tyrosine kinase activation may play an important role in mediating the effects of IL-1 $\beta$, while also suggesting that ST 638 has an inhibitory effect on the arteriosclerotic changes and vasospastic responses to autacoids in our swine model in vivo. (J. Clin. Invest. 1995. 96:12881294.) Key words: cytokine • tyrosine kinase - ST 638 • coronary vasospasm $\cdot$ growth factor
\end{abstract}

\section{Introduction}

Atherosclerosis is an excessive inflammatory and proliferative response of the vascular wall to various forms of injury (1-3). We previously developed a swine model of coronary artery spasm and revealed an intimate relationship between coronary spasm and atherosclerosis (4-6). However, it remains to be

Address correspondence to Hiroaki Shimokawa, Research Institute of Angiocardiology and Cardiovascular Clinic, Kyushu University School of Medicine, 3-1-1 Maidashi, Higashi-ku, Fukuoka 812, Japan. Phone:81-92-641-1151 ext. 2306; FAX:81-92-633-2742.

Received for publication 8 November 1994 and accepted in revised form 11 May 1995.

J. Clin. Invest.

(C) The American Society for Clinical Investigation, Inc.

0021-9738/95/09/1288/07 \$2.00

Volume 96, September 1995, 1288-1294 elucidated as to what aspect of coronary atherosclerosis is responsible for the occurrence of the spasm. We recently demonstrated that coronary arteriosclerotic changes and vasospastic responses to autacoids can be induced at the site of the coronary artery where IL- $1 \beta$, a major inflammatory cytokine found in atherosclerotic lesions, was chronically and locally applied (7). These results suggest that the inflammatory aspect of coronary atherosclerosis is important in the pathogenesis of coronary spasm. Furthermore, we also demonstrated that these changes were importantly mediated by PDGF (7).

Studies in vitro have revealed that the proliferation of smooth muscle cells may be mediated by several growth factors, such as PDGF (8), basic fibroblast growth factor (bFGF) ${ }^{1}$ (9) and IGF-1 (10). Thus, the administration of a neutralizing antibody against PDGF (11), bFGF (12), or IGF-1 (13) has been reported to be effective in suppressing neointimal formation after balloon injury. However, the approaches which target each of these growth factors may have critical limitations regarding their effectiveness in vivo because many growth factors and cytokines are sequentially and/or simultaneously induced in the cytokine network at such inflammatory/proliferative lesions (1, 14). The receptors for many growth factors, including PDGF (15), bFGF (16), and IGF-1 (17), are known to have tyrosine kinase activity. Thus, tyrosine kinases can be regarded as one of the common and key steps for smooth muscle proliferation. In this study, we examined whether or not the inhibition of tyrosine kinase activity suppresses the coronary arteriosclerotic changes and vasospastic responses to autacoids induced by chronic treatment with IL- $\beta$ in our swine model in vivo.

\section{Methods}

Animal preparation. 20 male domestic pigs weighing $23-27 \mathrm{~kg}$ were sedated with intramuscular administration of ketamine hydrochloride $(12.5 \mathrm{mg} / \mathrm{kg}$ ) and were anesthetized with intravenous administration of sodium pentobarbital $(25 \mathrm{mg} / \mathrm{kg}$ ). The animals were then intubated and ventilated by room air supplemented with oxygen via a positive pressure respirator. Under aseptic conditions, a left thoracotomy was performed and the proximal segments of the left anterior descending (LAD) and circumflex coronary artery (LCX) were carefully dissected. The dissected segments of the coronary artery were gently wrapped with cotton mesh soaked in $0.05 \mathrm{ml}$ suspension of one of the following agents: $(a)$ recombinant human $\mathrm{IL}-1 \beta(2.5 \mu \mathrm{g})$ bound to sepharose beads plus $1 \%$ Tween 80, a surfactant as a vehicle for ST 638; (b) IL-1 $\beta(2.5 \mu \mathrm{g})$ plus ST $638(2.5 \mathrm{mg}, n=5$ or $12.5 \mathrm{mg}, n=7)$, a selective tyrosine

1. Abbreviation used in this paper: bFGF, basic fibroblast growth factor. 
<smiles>N#C/C(=C\c1cc([18OH])c(O)c([18OH])c1)C(N)=O</smiles><smiles>N#CC(=Cc1ccc(O)cc1)C(N)=O</smiles>

Figure 1. The chemical structures of ST 638 and ST 494.

kinase inhibitor (18) (Fig. 1), dissolved in Tween 80; (c) IL-1 $\beta$ (2.5 $\mu \mathrm{g})$ plus ST $494(12.5 \mathrm{mg}, n=3)$, an inactive form of ST 638 (19) (Fig. 1); or (d) ST 638 (12.5 mg) alone (without Sepharose beads, $n$ $=3$ ). Only one segment of each coronary artery (LAD or LCX) was used. This experiment was reviewed by the Ethics Committee on Animal Experiments in the Kyushu University School of Medicine (Fukuoka, Japan), and was carried out under the Guidelines for Animal Experiments in the Kyushu University School of Medicine and The Law (No. 105 ) and Notification (No. 6) of the Japanese Government.

Preparation of $I L-1 \beta$ beads. 1 gram of Sepharose microbeads (CNBr-activated Sepharose 4B, 45-165 $\mu \mathrm{m}$ in diameter; Pharmacia Diagnostics AB, Uppsala, Sweden), which bind the amino residues of proteins, including cytokines, were added to $50 \mathrm{ml}$ of $1 \mathrm{mM} \mathrm{HCl}$ solution and centrifuged at $1,200 \mathrm{rpm}$ for $5 \mathrm{~min}$, four times. The beads were then resuspended in $20 \mathrm{ml}$ of $\mathrm{NaHCO}_{3} / \mathrm{NaCl}$ solution with $1 \mathrm{mg}$ of IL$1 \beta$. The beads were allowed to bind with $\mathrm{IL}-1 \beta$ at room temperature for $1 \mathrm{~h}$ and then at $4^{\circ} \mathrm{C}$ overnight. After centrifugation at $1,200 \mathrm{rpm}$ for $5 \mathrm{~min}$, the supernatant was separated and the concentration of the remaining IL- $1 \beta$ in the supernatant was measured by an ELISA. The IL$1 \beta$-bound beads in the pellet were resuspended in $20 \mathrm{ml}$ of $\mathrm{NaHCO}_{3} /$ $\mathrm{NaCl}$ solution and centrifuged at 1,200 rpm for $5 \mathrm{~min}$, four times. Then the IL- $1 \beta$-bound beads were resuspended with Tris/ $\mathrm{HCl}$ buffer solution for $1 \mathrm{~h}$ to block any remaining active sites. The $\mathrm{IL}-1 \beta$-bound beads were finally washed and resuspended so that the final concentration of IL- $1 \beta$ was $50 \mu \mathrm{g} / \mathrm{ml}$. The number of the IL- $1 \beta$ beads in the suspension was $\sim 70 / \mu$ l. All preparations mentioned above were performed under sterile conditions.

In a preliminary study, we confirmed that the Sepharose beads were not washed out by the local bloodstream and that the local effects of IL-1 $\beta$ were noted without causing any systemic effects (7). We have previously confirmed that with these techniques the Sepharose beads alone (without $\mathrm{IL}-1 \beta$ ) caused only mild coronary stenosis and did not induce any significant coronary hyperconstrictions to the same autacoids (serotonin and histamine) as used in this study (7).

Pharmacokinetics and bioavailability of ST 638. In a preliminary study, we measured the concentration of ST 638 in the porcine carotid artery treated with the agent $(12.5 \mathrm{mg})$ to elucidate the pharmacokinetics of ST 638 , using HPLC $(n=7)$. The average amount of ST 638 per 1 gram wet weight of the vessel $1,3,7$, and $14 \mathrm{~d}$ after the treatment were $602,651,288$, and $121 \mu \mathrm{g} / \mathrm{gram}$, respectively. Thus, the estimated local concentrations of ST 638 in the vessel wall 1, 3, 7, and $14 \mathrm{~d}$ after the treatment were $1.7,1.8,0.81$, and $0.34 \mathrm{mM}$, respectively, regarding 1 gram of wet weight of the vessel as $1 \mathrm{ml}$ of fluid. Those estimated local concentrations of ST 638 were 30-100 times higher than those which inhibit intracellular tyrosine kinases, such as tyrosine kinase of epidermal growth factor receptor (18).

Coronary angiography. 2 wk after the operation, the animals were again anesthetized and ventilated as described above, and coronary angiography in a left anterior oblique view was performed. The responses to the intracoronary administration of nitroglycerin $(10 \mu \mathrm{g} / \mathrm{kg})$, serotonin $(1,3$, and $10 \mu \mathrm{g} / \mathrm{kg})$, histamine $(1,3$, and $10 \mu \mathrm{g} / \mathrm{kg})$, and prostaglandin $F_{2 \alpha}(5$ and $50 \mu \mathrm{g} / \mathrm{kg}$ ) were examined. Coronary angiography was performed $2 \mathrm{~min}$ after the intracoronary administration of nitroglycerin and serotonin, $1 \mathrm{~min}$ after that of histamine, and $5 \mathrm{~min}$ after that of prostaglandin $F_{2 \alpha}$, when the hemodynamic variables returned to basal levels (20). Aortic pressure, heart rate and electrocardiograms (I, II, III, $V_{1}$, and $V_{6}$ leads) were continuously recorded during the coronary angiographic study $(4-7,20)$.

Coronary diameter measurement. Cineangiograms were projected on a screen using a cineprojector (ELK-35CB; Nishimoto Sangyo Inc., Osaka, Japan) and an end diastolic frame was chosen and printed. The coronary luminal diameters were measured with a caliper (4-7). Using this technique, excellent correlations between repeated measurements $(r=0.99)$ and between different observers $(r=0.98)$ were confirmed in the range of the coronary diameter from 0.98 to $5.58 \mathrm{~mm}(20)$. Coronary stenosis of the drug-treated segments was expressed as the percent decrease in the luminal diameter compared to the mean diameter of adjacent proximal and distal nonstenotic coronary segments after the intracoronary administration of nitroglycerin $(10 \mu \mathrm{g} / \mathrm{kg})$. The responses to serotonin, histamine, and prostaglandin $F_{2 \alpha}$ were expressed as the percentage of luminal narrowing compared to the coronary luminal diameter after the intracoronary administration of nitroglycerin (10 $\mu \mathrm{g} / \mathrm{kg}$ ).

Histological examination. On completion of the angiographic experiments, all animals were killed with a lethal dose of intravenous sodium pentobarbital and the hearts were removed. The left coronary arteries were then perfused via a constant pressure perfusion system $(120 \mathrm{~cm}$ $\mathrm{H}_{2} \mathrm{O}$ ) with saline $(500 \mathrm{ml})$ and subsequently with $6 \%$ formaldehyde $(1,000 \mathrm{ml})$. After fixation, both left anterior descending and left circumflex coronary arteries were cut transversely into segments at 5-mm intervals along their main trunk with small portions of the surrounding tissue. These segments were stained with hematoxylin and eosin and van Gieson's elastic staining for photomicroscopy.

With a photomicroscopic photograph system (MICROPHOT-FXA; Nikon Co., Tokyo, Japan), pictures of the coronary arteries were taken at a magnification of 40 , and the degree of intimal thickening was analyzed quantitatively using a computer-assisted picture analysis system (Genlocker System; Sony Corp., Tokyo, Japan). This system consists of a high resolution television monitor, an image processing and calculation unit with a microprocessor, a light pen controller with a microprocessor, and a printer. The inner border of the intimal layer and the internal elastic lamina were traced by the light pen, and the areas encircled by the tracings were calculated automatically. The intimal area (Ai) was calculated by the formula $\mathrm{Ai}=\mathrm{Ae}-\mathrm{Al}$, where $\mathrm{Ae}$ and $\mathrm{Al}$ are the areas within the internal elastic lamina and the internal border of the vessel (luminal area), respectively. The degree of intimal thickening was expressed by the following three parameters; intimal area $=\mathrm{Ai}\left(\mathrm{mm}^{2}\right)$, maximal intimal thickness $(\mathrm{mm})$ measured with a caliper, and percent intima that was calculated by the following equation; $\mathrm{Ai}$ / Ae $\times 100(\%)$.

Antiphosphotyrosine immunoblotting. The other three pigs were killed for antiphosphtyrosine immunoblotting $14 \mathrm{~d}$ after the operation with the IL-1 $\beta$ treatment. These animals did not undergo the angiographic study to avoid any possible influences of the experiment on the phosphotyrosine levels. In these animals, the hearts were removed, and the coronary arterial segments treated with $\mathrm{IL}-1 \beta(2.5 \mu \mathrm{g}), \mathrm{IL}-1 \beta(2.5$ $\mu \mathrm{g})$ plus ST $638(12.5 \mathrm{mg})$, and the untreated segments were dissected. Next, each segment was homogenized in an extraction buffer (containing $62 \mathrm{mM}$ Tris- $\mathrm{HCl}, 2.5 \mathrm{mM} \mathrm{MgCl} 2,1.0 \mathrm{mM}$ EGTA, $1 \%$ sodium dodecyl sulfate, $1 \%$ Triton $\mathrm{X}-100,100 \mathrm{U} / \mathrm{ml}$ aprotinine, $12 \mu \mathrm{M} p$ amidinophenyl methanesulfonyl fluoride [pAPMSF], $25 \mu \mathrm{M}$ leupeptin, 

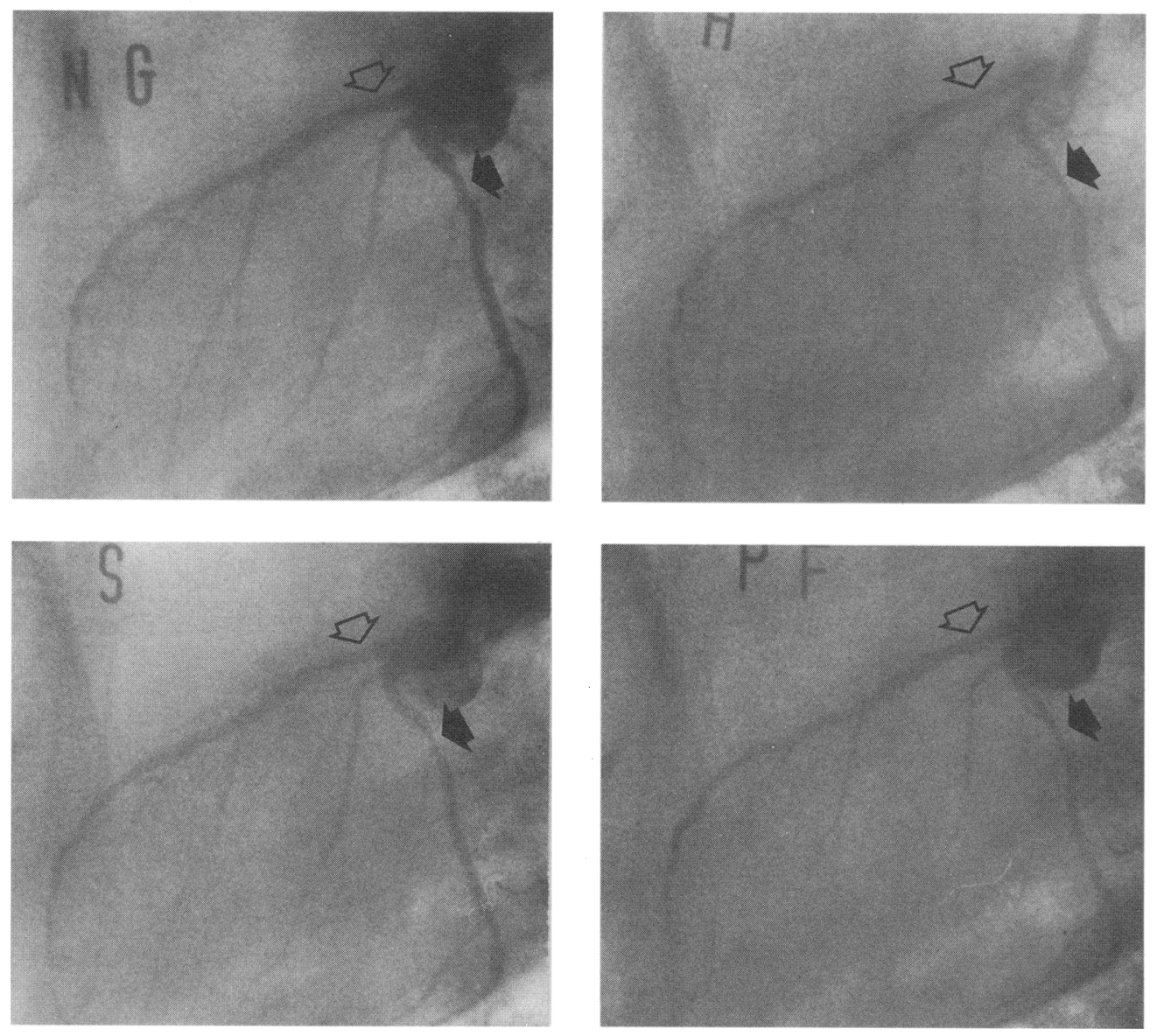

Figure 2. Coronary angiograms of the left coronary artery after the intracoronary administration of nitroglycerin $(10 \mu \mathrm{g} / \mathrm{kg})(N G$, top left $)$, serotonin $(10 \mu / \mathrm{kg})(\mathrm{S}$, bottom left $)$, histamine $(10 \mu \mathrm{g} / \mathrm{kg})$ $(H$, top right $)$, and prostaglandin $\mathrm{F}_{2 \alpha}(50 \mu \mathrm{g} / \mathrm{kg})(P F$, bottom right). Black and translucent arrows, respectively, indicate the coronary artery segments treated with IL-1 $\beta(2.5 \mu \mathrm{g})$ and $\mathrm{IL}-1 \beta$ $(2.5 \mu \mathrm{g})$ plus ST $638(12.5 \mathrm{mg})$.

$5 \mu \mathrm{M}$ [L-3-trans-carboxyoxiran-2-carbonyl]-L-Leu-agmatin [E-64], and $200 \mu \mathrm{M}$ orthovanadate). The cell lysate was centrifuged at 12,000 $\mathrm{rpm}$ for $30 \mathrm{~min}$ at $4^{\circ} \mathrm{C}$. The supernatant was subjected to SDS-polyacrylamid gel electrophoresis, and transferred to polyvinylidene difluoride membrane. Then immunoblotting was performed using monoclonal antiphosphotyrosine antibody (PY20; ICN Biomedicals Inc., Irvine, CA.) (21) and detected by horseradish peroxidase-coupled goat anti-mouse IgG and chemiluminescence (22). The amounts of total protein per lane were equally $25 \mu \mathrm{g}$. The antiphosphotyrosine antibody does not crossreact with phosphoserine or phosphothreonine (22).

In the present assay, we used 1-5 $\mu \mathrm{g} / \mathrm{ml}$ of antiphosphotyrosine antibody $(21,22)$. However, it has not been clarified how many phosphotyrosine residues per protein or how many protein molecules that contain phosphotyrosine residues are necessary for the detection of phosphotyrosine residues. However, our technique can detect more than a 10-fold difference in the phosphotyrosine contents between carcinomatous rat fibroblasts and normal rat fibroblasts (22). In addition, our technique can detect the phosphotyrosine contents in normal cells when the exposure time for enzyme-linked chemiluminescence is prolonged (22).

Drugs. The following drugs were used: recombinant human IL$1 \beta$ (Ohtsuka Pharmaceutical Co., Tokyo, Japan), ST 638 ( $\alpha$-cyano-3ethoxy-4-hydroxy-5-phenyl-methylcinnamamide) (18) and ST 494 ( $\alpha$ cyano-4-hydroxy-cinnamamide) (19) (Kanegafuchi Chemical Co., Osaka, Japan) (Fig. 1); 5-hydroxytryptamine ( serotonin) and histamine (Sigma Chemical Co., St. Louis, MO), nitroglycerin (Nihon-kayaku Pharmaceutical Co., Tokyo, Japan) and prostaglandin $\mathrm{F}_{2 \alpha}$ (Ono Pharmaceutical Co., Osaka, Japan). ST 638 and ST 494 were dissolved in 1\% Tween 80 . Tween 80 alone did not affect the coronary diameter. Serotonin and histamine were dissolved in physiological saline.

Statistical analysis. The results were expressed as the mean \pm SEM.
Multiple comparisons were made by an ANOVA, and if a significant $F$ value was found, Scheffe's test for multiple comparisons was used to identify any differences among the groups. Paired data were analyzed by Student's $t$ test. A $P$ value of $<0.05$ was considered to be statistically significant.

\section{Results}

After the operation, a moderately stenotic coronary lesion developed angiographically at the site treated with IL- $\beta(2.5 \mu \mathrm{g})$ (Figs. 2 and 3 ). The intracoronary administration of serotonin and histamine caused marked coronary vasoconstriction at the $\mathrm{IL}-1 \beta$-treated site (Figs. 2 and 3 ). In contrast, the intracoronary administration of prostaglandin $\mathrm{F}_{2 \alpha}$ caused a comparable degree of coronary vasoconstriction at the $\mathrm{IL}-1 \beta$-treated and at the untreated sites (Figs. 2 and 3).

The coronary stenosis at the IL- $\beta$-treated site was not inhibited by cotreatment with a low dose of ST $638(2.5 \mathrm{mg})$ (Fig. 3), but was significantly inhibited by that with a high dose of ST 638 (12.5 mg) (Figs. 2 and 3). In contrast, ST 494 $(12.5 \mathrm{mg}$ ), which is an inactive form of ST 638 , did not inhibit the IL- $1 \beta$-induced coronary stenosis $(48 \pm 2$ and $41 \pm 13 \%$, at the sites treated with $\mathrm{IL}-1 \beta$ alone and with $\mathrm{IL}-1 \beta$ plus ST 494 , respectively, $n=3$ ).

The coronary hyperconstriction to intracoronary serotonin tended to be suppressed at the site treated with a low dose of ST $638(2.5 \mathrm{mg}$ ) (Fig. 3) and was significantly suppressed at the site treated with a high dose of ST 638 (12.5 mg) (Figs. 2 

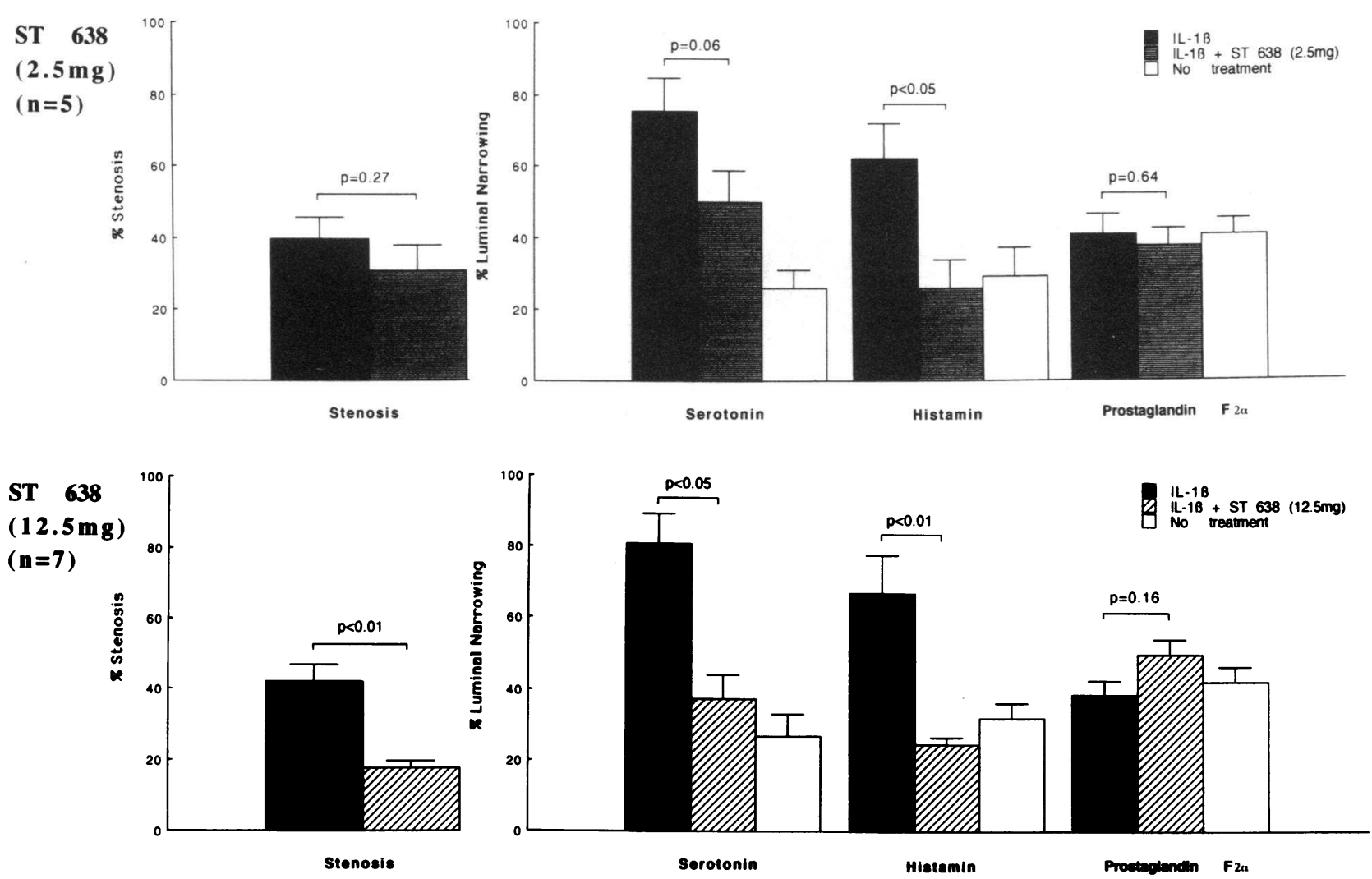

Figure 3. Effects of ST 638 on coronary stenosis (\% Stenosis) and vasospastic responses (\% Luminal Narrowing) induced by chronic treatment with IL-1 $\beta$. (Upper panels) Coronary stenosis induced by $\mathrm{IL}-1 \beta(2.5 \mu \mathrm{g}$ ) (closed bar) was not inhibited by cotreatment with a low dose of ST $638(2.5 \mathrm{mg})$ (hatched bar). Coronary vasospastic response to serotonin $(10 \mu \mathrm{g} / \mathrm{kg})$ at the $\mathrm{IL}-1 \beta$-treated site (closed bar) tended to be inhibited and that to histamine $(10 \mu \mathrm{g} / \mathrm{kg})$ was significantly inhibited by cotreatment with a low dose of ST $638(2.5 \mathrm{mg})$ (hatched bar). Intracoronary prostaglandin $\mathrm{F}_{2 \alpha}(50 \mu \mathrm{g} / \mathrm{kg}$ ) caused a comparable degree of vasoconstriction at the IL-1 $\beta$-treated (closed bar), the IL-1 $\beta$ plus ST 638 ( $2.5 \mathrm{mg}$ ) treated (hatched bar), and the untreated sites (open bar). (Lower panels) Coronary stenosis and vasospastic responses to the autacoids at the IL$1 \beta(2.5 \mu \mathrm{g})$-treated site (closed bar) were all significantly inhibited by cotreatment with a high dose of ST 638 (12.5 mg) (hatched bar). Intracoronary prostaglandin $\mathrm{F}_{2 \alpha}$ caused a comparable degree of vasoconstriction at the IL-1 $\beta$-treated (closed bar), the IL-1 $\beta$ plus ST 638 (12.5 $\mathrm{mg}$ ) -treated (hatched bar), and the untreated sites (open bar).

and 3). The histamine-induced coronary hyperconstriction at the IL- $1 \beta$-treated site was also significantly suppressed by cotreatment with ST 638 at $2.5 \mathrm{mg}$ (Fig. 3) and at $12.5 \mathrm{mg}$ (Figs. 2 and 3 ). In contrast, ST 494 did not suppress those vasospastic responses to either serotonin $(61 \pm 23$ and $52 \pm 9 \%)$ or to histamine ( $52 \pm 26$ and $45 \pm 10 \%$, at the sites treated with $I L-1 \beta$ alone and with IL- $1 \beta$ plus ST 494 , respectively, $n=3$ ). In addition, treatment with ST $638(12.5 \mathrm{mg})$ alone did not affect the coronary vasoconstriction to the autacoids (data not shown, $n=3$ ). In contrast, prostaglandin $\mathrm{F}_{2 \alpha}$-induced coronary vasoconstriction at the IL- $1 \beta$-treated site was not significantly affected by cotreatment with either ST 638 (Figs. 2 and 3) or ST 494 (data not shown).

A histological examination revealed that intimal thickening was induced at the IL- $1 \beta$-treated site (Fig. 4), which was inhibited by cotreatment with ST $638(12.5 \mathrm{mg}$ ) (Fig. 4). A quantitative analysis of the intimal thickening showed that a high dose of ST $638(12.5 \mathrm{mg})$ significantly suppressed all three parameters, while a low dose of ST $638(2.5 \mathrm{mg})$ did not (Fig. 5).

Antiphosphotyrosine immunoblotting showed that 2 wk after the operation the levels of phosphotyrosine-containing pro- teins $(34,48,52,70,100,130$, and $150 \mathrm{kDs})$ were elevated at the coronary artery segment treated with $\mathrm{IL}-1 \beta$, while, in addition, cotreatment with ST $638(12.5 \mathrm{mg})$ suppressed to a variable degree the elevation of those phosphotyrosine-containing proteins (Fig. 6).

\section{Discussion}

The major findings of this study were $(a)$ tyrosine kinases played an important role in mediating the effects of IL- $1 \beta$ in vivo and (b) ST 638, a selective inhibitor of tyrosine kinases, exerted inhibitory effects on the arteriosclerotic changes and vasospastic responses to autacoids in our swine model in vivo. To our knowledge, this is the first in vivo demonstration of the inhibitory effects of a tyrosine kinase inhibitor on the development of intimal lesions and hyperconstrictive responses after vascular injury.

Coronary arteriosclerosis and tyrosine kinase activity. We used IL- $1 \beta$ as an inflammatory cytokine to induce arteriosclerotic changes and vasospastic responses to autacoids (7), based on the fact that $\mathrm{IL}-1 \beta$ is highly inflammatory and is also one of the major inflammatory cytokines found in atherosclerotic 


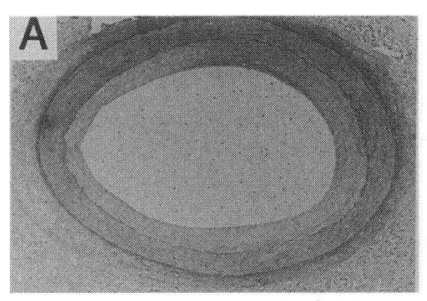

$1 L-1 \beta$

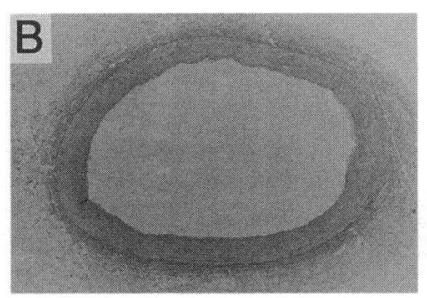

IL-1 $\beta+$ ST $638(12.5 \mathrm{mg})$

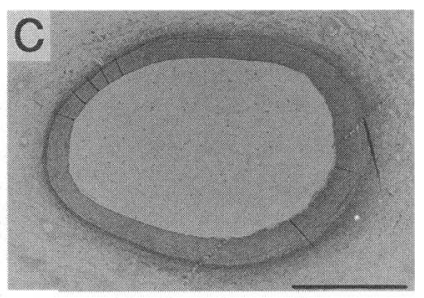

No treatment
Figure 4. Effects of ST 638 ( 12.5 $m g$ ) on the histological changes of the coronary artery induced by chronic treatment with IL- $1 \beta$. The intimal thickening at the IL- $1 \beta$ $(2.5 \mu \mathrm{g})$-treated site $(A)$ was inhibited by cotreatment with ST $638(12.5 \mathrm{mg})(B) . C$ shows the untreated coronary artery segment without intimal lesion. The bar in $C$ represents $1 \mathrm{~mm}$. lesions $(23,24)$. Studies in vitro have shown that IL- $1 \beta$ is not only an inflammatory cytokine but also a growth factor for smooth muscle cells $(25,26)$. However, IL- $1 \beta$ does not exert any direct mitogenic activity on smooth muscle cells in vitro and its proliferative effects are mediated by other growth factors, mainly by PDGF, which are induced in and released by fibroblasts and smooth muscle cells in response to IL-1 $\beta$ (8). Furthermore, we have also demonstrated in vivo that the atherogenic and spasmogenic effects of IL- $1 \beta$ are importantly mediated by PDGF (7) and bFGF (Ito, A., H. Shimokawa, T. Kadokami, Y. Fukumoto, M. Koji Owada, T. Shiraishi, R. Nakaike, T. Takayanagi, K. Egashira, and A. Takeshita, unpublished observations). The receptors for these growth factors are also known to have tyrosine kinase activity $(15,16)$. Indeed, the present result of the antiphosphotyrosine immunoblotting demonstrated that tyrosine phosphorylation was elevated at the IL-
$1 \beta$-treated site of the coronary artery, which suggests that tyrosine kinases were activated at this inflammatory coronary lesion. In the present study, tyrosine kinases were thought to be activated as late as $14 \mathrm{~d}$ after the IL- $1 \beta$ treatment. This was probably because several growth factors were sequentially and/or simultaneously induced in the cytokine network at the IL- $1 \beta$ treated site at least for $2 \mathrm{wk}(1-3)$. However, we can not rule out the possibility that IL- $1 \beta$ also inhibited the phosphotyrosine phosphatases and eventually increased the tyrosine phosphorylations to some extents.

Antiproliferative effects of a selective inhibitor of tyrosine kinases. ST 638 potently inhibits tyrosine-specific kinase activity of the epidermal growth factor receptor with a $50 \%$ inhibitory concentration value of $0.37 \mu \mathrm{M}$, and has no inhibitory effect on the enzymes of serine- or threonine-specific protein kinases, such as cAMP-dependent protein kinase, $\mathrm{Ca}^{2+} /$ phos-

\section{ST 638} $(2.5 \mathrm{mg})$ $(n=4)$
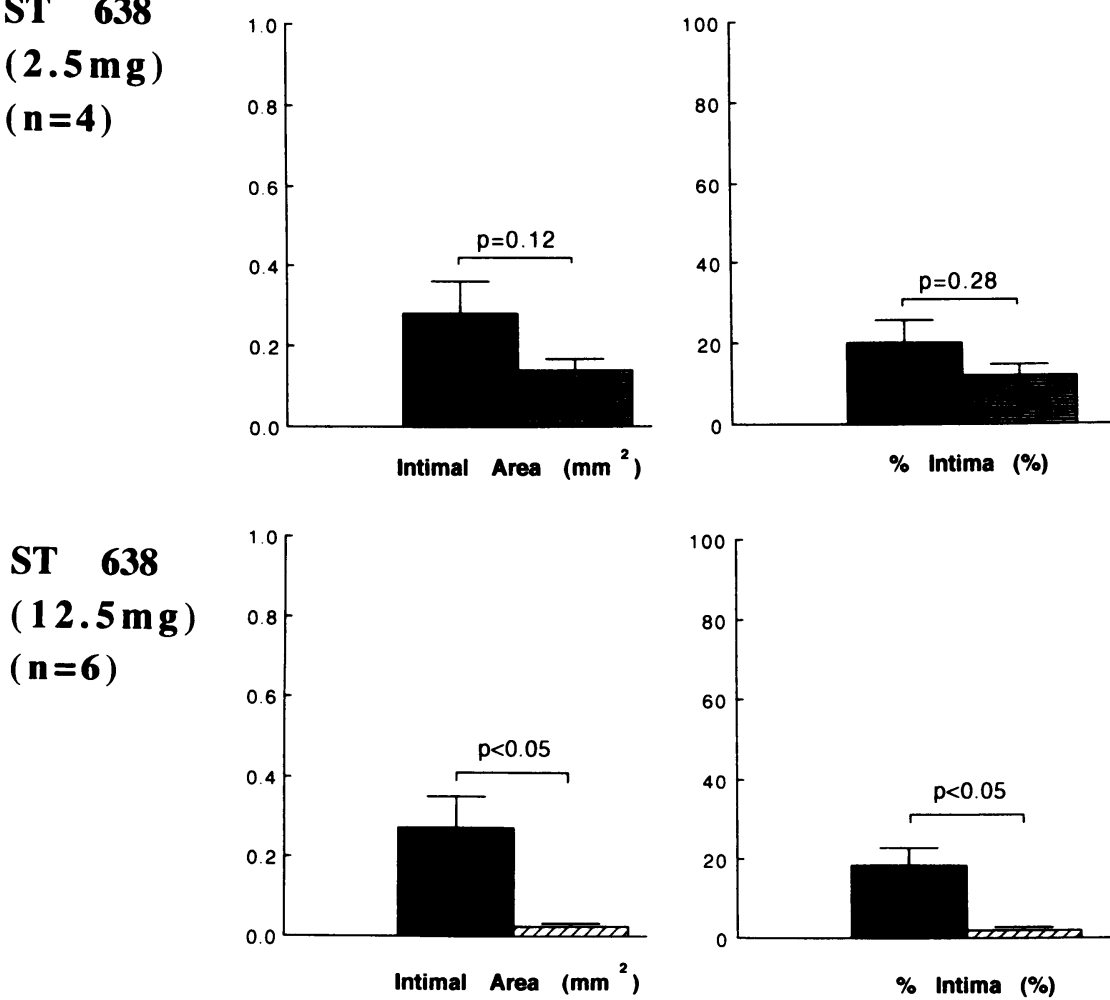

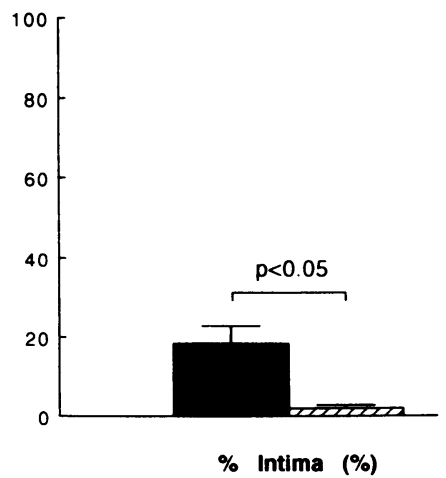

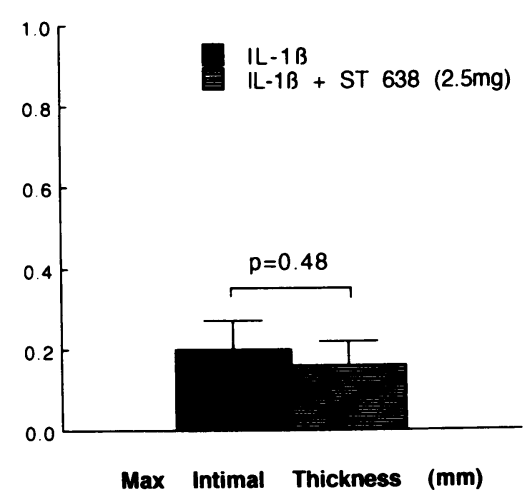

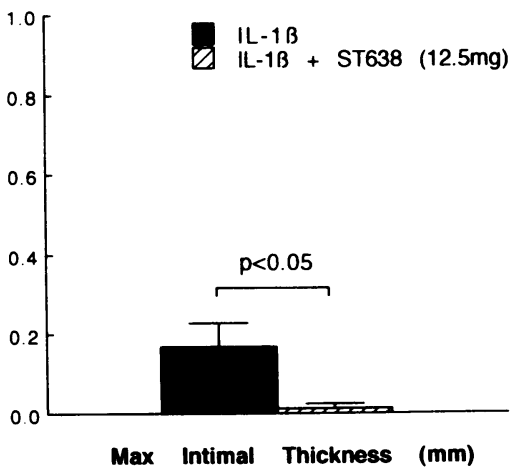

Figure 5. Effects of ST 638 on coronary intimal thickening induced by chronic treatment with IL-1 $\beta$. (Upper panel) Intimal thickening induced by IL-1 $\beta(2.5 \mu \mathrm{g}$ ) (closed bar) was not inhibited by co-treatment with a low dose of ST 638 ( $2.5 \mathrm{mg})$ (hatched bar). (Lower panel) Intimal thickening induced by IL-1 $\beta$ (closed bar) was significantly inhibited by co-treatment with a high dose of ST 638 (12.5 mg) (hatched bar). 


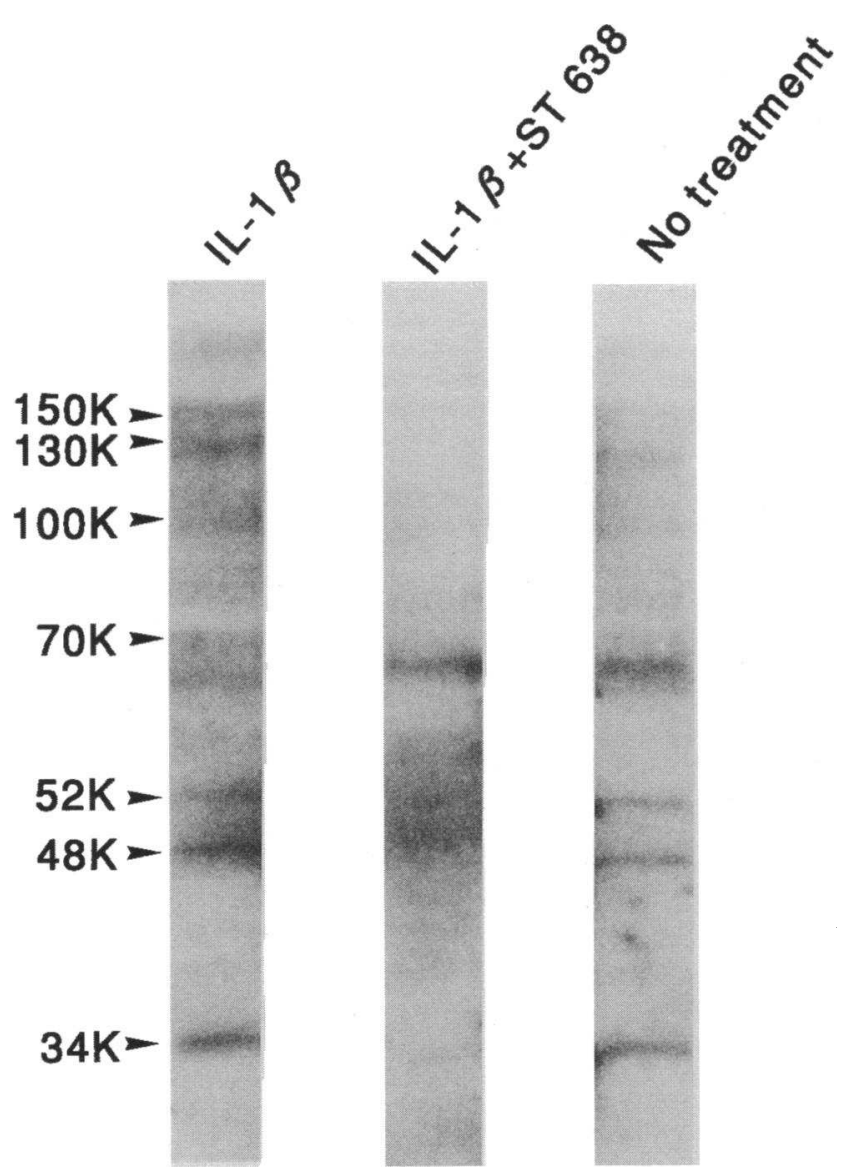

Figure 6. Inhibitory effects of ST $638(12.5 \mathrm{mg})$ on the elevated levels of phosphotyrosine-containing proteins induced by IL- $1 \beta$ (antiphosphotyrosine immunoblotting). Tyrosine phosphorylation was increased at the IL- $1 \beta(2.5 \mu \mathrm{g})$-treated site (left lane). The elevated tyrosine phosphorylation induced by IL- $1 \beta$ was inhibited to a variable degree by cotreatment with ST 638 (12.5 mg) (middle lane). The right lane shows low levels of tyrosine phosphorylation at the untreated site.

pholipid-dependent protein kinase C, casein kinase I and casein kinase II (18). Thus, ST 638 is a potent and specific inhibitor of tyrosine kinases (18). Its inhibitory effect is mediated by competing with the substrate protein for the tyrosine kinase binding site (19).

In a preliminary study, we confirmed that ST 638 remained locally at sufficient concentrations to exert its effect as late as $14 \mathrm{~d}$ after the application. We also confirmed recently that ST 638 inhibits the proliferation of cultured smooth muscle cells of the rat aorta induced by PDGF (Kozai, T., H. Shimokawa, A. Ito, Y. Fukumoto, S. Kobayashi, H. Kanaide, and A. Takeshita, unpublished observations). The present study has confirmed that this is also the case in vivo and that cotreatment with ST 638 suppresses the activation of several tyrosine kinases induced by $\mathrm{IL}-1 \beta$ to a variable degree as shown by antiphosphotyrosine immunoblotting. Several weak levels of phosphotyrosine proteins were detected in the untreated vessel, which may indicate that several tyrosine kinases were necessary for the function of normal vessels. These results suggest that the antiproliferative effects of ST 638 observed in this study are likely due to the inhibition of tyrosine kinases.

Coronary vasospastic responses and tyrosine kinases. An- other important finding of the present study was that coronary vasospastic responses to the autacoids induced by chronic treatment with IL-1 $\beta$ were inhibited by cotreatment with ST 638 . It has been reported that tyrosine kinase inhibitor attenuates smooth muscle contraction to several agonists in vitro (27). In the present study, however, treatment of coronary artery with ST 638 alone did not affect the coronary vasoconstriction to the autacoids or prostaglandin $F_{2 \alpha}$. Therefore, the inhibitory effects of ST 638 on the coronary vasospastic responses may be due to the suppression of the inflammatory/proliferative changes induced by $\mathrm{IL}-1 \beta$ but not due to a direct inhibition of the coronary vasoconstriction.

We have recently demonstrated that intracellular pathway mediated by protein kinase C (PKC) plays an important role in the pathogenesis of coronary spasm at the atherosclerotic lesion induced by a combination of balloon endothelial denudation, x-ray irradiation and a high-cholesterol feeding (20). Recently, we have observed that PKC-mediated pathway also plays an important role in the pathogenesis of coronary spasm in the present model with IL-1 $\beta$ (28). Thus, there appears to be an important link between the arteriosclerotic changes mediated by tyrosine kinases and the altered PKC-mediated pathway in the pathogenesis of coronary artery spasm $(20,28)$.

Clinical implications. The pathogenesis of the restenotic process after coronary angioplasty is incompletely understood but appears to be multifactorial (1). One of the principal factors is the stimulation of smooth muscle proliferation by growth factors (1). Several in vivo studies have revealed that the administration of a neutralizing antibody against PDGF (11), bFGF (12), or IGF-1 (13) suppresses the neointimal formation after balloon angioplasty. However, these approaches targetting each of these growth factors may have critical limitations in their effectiveness in vivo because many growth factors and cytokines are sequentially and/or simultaneously induced in the cytokine network at the inflammatory/proliferative lesions (1, 14). In contrast, tyrosine kinases could be regarded as one of the common and key steps for smooth muscle proliferation (1517). In the present study, we demonstrated that ST 638 , a selective inhibitor of tyrosine kinases, has an inhibitory effect on the arteriosclerotic changes and vasospastic responses to the autacoids induced by chronic treatment with $\mathrm{IL}-1 \beta$ in our swine model in vivo. Further studies are needed to examine whether or not tyrosine kinase inhibitors also suppress the neointimal formation after coronary angioplasty.

\section{Acknowledgments}

The authors wish to thank Drs. Sei Kobayashi, Kyushu University, and Takuya Kishimoto and Chiharu Imada, Kyoto Pharmaceutical University, for their cooperation in this study and Mika Mizokami and Tomoko Takebe for their excellent technical assistance.

This work was supported in part by the grants from the Ministry of Education, Science and Culture (No. 02404045, No. 04670540, No. 06454274), Tokyo, Japan; the Ministry of Health and Welfare (No. 6C-2), Tokyo, Japan; by grants-in-aid from the Sandoz Foundation for Gerontological Research; the Japan Research Foundation for Clinical Pharmacology; and the Japanese Medical Association.

\section{References}

1. Ross, R. 1993. The pathogenesis of atherosclerosis: a perspective for the 1990s. Nature (Lond.). 362:801-809. 
2. Munro, J. M., and R. S. Cotran. 1988. Biology of disease: the pathogenesis of atherosclerosis: atherogenesis and inflammation. Lab. Invest. 58:249-261.

3. Hansosn, G. K., L. Jonasson, P. S. Seifert, and S. Stemme. 1989. Immune mechanisms in atherosclerosis. Arteriosclerosis. 9:567-578.

4. Shimokawa, H., H. Tomoike, S. Nabeyama, H. Yamamoto, H. Araki, M. Nakamura, Y. Ishii, and K. Tanaka. 1983. Coronary artery spasm induced in atherosclerotic miniature swine. Science (Wash. DC). 221:560-562.

5. Shimokawa, H., H. Tomoike, S. Nabeyama, H. Yamamoto, Y. Ishii, K. Tanaka, and M. Nakamura. 1985. Coronary artery spasm induced in miniature swine: angiographic evidence and relation to coronary atherosclerosis. Am. Heart. J. 110:300-310.

6. Egashira, K., H. Tomoike, H. Yamamoto, A. Yamada, Y. Hayashi, and M. Nakamura. 1986. Histamine-induced coronary spasm in regions of intimal thickening in miniature pigs: roles of serum cholesterol and spontaneous or induced intimal thickening. Circulation. 74:826-837.

7. Ito, A., H. Shimokawa, R. Nakaike, M. Sakata, T. Takayanagi, and A. Takeshita. 1993. Chronic treatment with interleukin-1 $\beta$ causes vasospastic response to autacoids in porcine coronary arteries in vivo. Circulation. 88(Suppl. I): I-374.

8. Ross, R., J. Glomset, B. Kariya, and L. Harker. 1974. A platelet-dependent serum factor that stimulates the proliferation of arterial smooth muscle cells in vitro. Proc. Natl. Acad. Sci. USA. 71:1207-1210.

9. Winkles, J. A., R. Friesel, W. H. Burgess, R. Howk, T. Mehlman, R. Weinstein, and T. Maciag. 1987. Human vascular smooth muscle cells both express and respond to heparin-binding growth factor I (endothelial cell growth factor). Proc. Natl. Acad. Sci. USA. 84:7124-7128.

10. Banskota, N. K., R. Taub, K. Zellner, P. Olsen, and G. L. King. 1989. Characterization of induction of protooncogene c-myc and cellular growth in human vascular smooth muscle cells by insulin and IGF-1. Diabetes. 38:123129.

11. Ferns, G. A., E. W. Raines, K. H. Sprugel, A. S. Motani, M. A. Reidy, and R. Ross. 1991. Inhibition of neointimal smooth muscle accumulation after angioplasty by an antibody to PDGF. Science (Wash. DC). 253:1129-1132

12. Linder, V., and M. A. Reidy. 1991. Proliferation of smooth muscle cells after vascular injury is inhibited by an antibody against basic fibroblast growth factor. Proc. Natl. Acad. Sci. USA. 88:3739-3743.

13. Grant, M. B., T. J. Wargovich, E. A. Ellis, S. Cabellero, M. Mansour, and C. J. Pepine. 1994. Localization of insulin-like growth factor I and inhibition of coronary smooth muscle cell growth by somatostatin analogues in human coronary smooth muscle cells. A potential treatment for restenosis? Circulation. 89:1511 1517.

14. Ross, R. 1986. The pathogenesis of atherosclerosis: an update. N. Engl. J. Med. 314:488-500.

15. Ek, B., B. Westemark, A. Wasteson, and C.-H. Heldin. 1982. Stimulation of tyrosine-specific phosphorylation by platelet-derived growth factor. Nature (Lond.). 295:419-420.

16. Hanks, S. K., A. M. Quinn, and T. Hunter. 1988. The protein kinase family: conserved features and deduced phylogeny of the catalytic domains. Science (Wash. DC). 241:42-52.

17. Ullrich, A., J. R. Bell, E. Y. Chen, R. Herrera, L. M. Petruzzelli, T. J. Dull, A. Gray, L. Coussens, Y.-C. Liao, M. Tsubokawa, et al. 1985. Human insulin receptor and its relationship to the tyrosine kinase family of oncogenes. Nature (Lond.). 313:756-761.

18. Shiraishi, T., T. Domoto, N. Imai, Y. Shimada, and K. Watanabe. 1987. Specific inhibitors of tyrosine-specific protein kinase, synthetic 4-hydroxycinnamamide derivaties. Biochem. Biophys. Res. Commun. 147:322-328.

19. Shiraishi, T., M. K. Owada, M. Tatsuka, T. Yamashita, K. Watanabe, and T. Kakunaga. 1987. Specific inhibitor of tyrosine-specific protein kinases: properties of 4-hydroxycinnamamide derivaties in vitro. Cancer Res. 49:23742378.

20. Ito, A., H. Shimokawa, R. Nakaike, T. Fukai, M. Sakata, T. Takayanagi, K. Egashira, and A. Takeshita. 1994. Role of protein kinase C-mediated pathway in the pathogenesis of coronary artery spasm in a swine model. Circulation. 90: 2425-2431.

21. Glenney, J. R., W. S. Chen, C. S. Lazar, G. M. Walton, L. M. Zokas, M. G. Rosenfeld, and G. N. Gill. 1988. Ligand-induced endocytosis of the EGF receptor is blocked by mutational inactivation and by microinjection of antiphosphotyrosine antibodies. J. Clin. Invest. 82:675-684.

22. Owada, M. K., M. Iwamoto, T. Koike, and Y. Kato. 1989. Effects of vanadate on tyrosine phosphorylation and the pattern on tyrosine phosphorylation and the pattern of glycosaminoglycan synthesis in rabbit chondrocytes in culture. J. Cell. Physiol. 138:484-492.

23. Dinarello, C. A. 1988. Biology of interleukin-1. FASEB (Fed. Am. Soc. Exp. Biol.) J. 2:108-115.

24. Moyer, C. F., D. Sajuthi, H. Tulli, and J. K. Williams. 1991. Synthesis of IL-1 alpha and IL-1 beta by arterial cells in atherosclerosis. Am. J. Pathol. 138:951-960.

25. Libby, P., S. J. C. Warner, G. Friedman. 1988. Interleukin 1: a mitogen for human vascular smooth muscle cells that induces the release of growthinhibitory prostanoids. J. Clin. Invest. 81:487-498.

26. Ikeda, U., M. Ikeda, T. Oohara, S. Kano, T. Yaginuma. 1990. Mitogenic action of interleukin-1 on vascular smooth muscle cells mediated by PDGF. Atherosclerosis. 84:183-188.

27. Di Salvo, J., A. Steusloff, L. Semenchuk, S. Satoh, K. Kolquist, and G. Pfitzer. 1993. Tyrosine kinase inhibitors suppress agonist-induced contraction in smooth muscle. Biochem. Biophys. Res. Commun. 190:968-974.

28. Kadokami, T., H. Shimokawa, A. Ito, Y. Fukumoto, T. Takayanagi, and K. Egashira. 1994. Activation of protein kinase $C$ induces coronary vasospasm at the interlrukin- $1 \beta$-induced inflammatory/ proliferative lesion in a swine model in vivo. Circulation. 90 (Suppl. I): I-258. 